\title{
The Influence of Corporate Front-Group Stealth Campaigns
}

\author{
Michael Pfau \\ Michel M. Haigh \\ Jeanetta Sims \\ Shelley Wigley \\ University of Oklahoma, Norman
}

\begin{abstract}
This research examined corporate front-group stealth campaigns. An experiment was conducted to examine the influence of front-group stealth campaigns on a variety of measures. It was anticipated that corporate front-group stealth campaigns, which feature names that mask the true interests of sponsors, positively affect public opinion, unless they are exposed as intentionally misleading, in which case they boomerang against sponsors. The experiment examined the potential of the inoculation strategy to preempt the influence of corporate front-group stealth campaigns. The pattern of results supported all of these expectations. Front-group stealth campaigns proved to be effective, at least in the short term. Front-group stealth campaigns eroded public attitudes toward the issue in question and boosted perceptions of the front group, but not the corporate sponsor. However, when front-group stealth campaigns were subsequently exposed, positive effects dissipated and perceptions of corporate sponsors boomeranged. Results revealed that inoculation can protect against the influence of front-group stealth campaigns.
\end{abstract}

Keywords: front group; inoculation; stealth campaign

The realms of advertising and public relations, and the nowadays closely related realm of politics, are replete with instances of bullshit so unmitigated that they can serve among the most indisputable and classic paradigms of the concept.

-Harry G. Frankfurt (2005, p. 22)

The current study examines the influence of corporate front-group stealth campaigns. Corporate front-group stealth campaigns are based on systematic efforts to deceive receivers. When companies work together collectively, adopting names that disguise true interests, they are utilizing front groups; when front groups engage in campaigns using names that deceive, they are engaged in stealth. This investigation examines the influence of this approach, which is based on corporations behaving badly, engaged in conscious deception. In addition, the current study assesses two 
potential antidotes to corporate front-group stealth campaigns: the post hoc exposure of front-group stealth initiatives and preemptive inoculation.

Front-group stealth campaigns involve sponsors, sometimes individually, but much more often collectively through interest groups, seeking to influence public opinion using deceptive names. Although a number of corporations, including Dow Chemical, Mobil, Ford, and Philip Morris, participate in corporate front-group stealth campaigns (Beder, 1998), no empirical studies have examined their influence on public opinion. The current study initially examines the influence of corporate frontgroup stealth campaigns on perceptions of the image, reputation, credibility, and citizenship of collective associations and their corporate sponsors.

We would like to believe that deceptive practices are ineffective. However, we suspect that deceptive efforts are persuasive. It is clear that corporate front-group stealth campaigns have grown more prevalent (Beder, 1998). The critical question is, What can be done about it? This investigation posits that preemption and post hoc exposure are effective strategies for undermining the effectiveness of front-group stealth campaigns and then tests this premise.

\section{Origin and Nature of Front-Group Stealth Campaigns}

Front groups, or "independent third-party groups," were first used by Edward Bernays (Stauber \& Rampton, 1995). Third-party endorsement or "outreach" (Reilly, 2003 ) is a long-standing public relations strategy. The assumption is that organizations not connected to the sponsor have greater credibility and, therefore, are more influential. Third-party endorsements are considered to be a "successful" public relations campaign strategy ("Third-Party," 2003).

The difference between ethical uses of third-party endorsement and the use of front groups is subtle. Ethical use of third-party endorsement relies on existing groups that are well known and credible, whereas front groups are usually created by sponsors for the purpose of shielding their identity. According to the Public Relations Society (PRSA) of America, front groups seek to influence "by disguising or obscuring the true identity of their members or implying representation of a much more broadly based group" ("PRSA Speaking Out," 1995, p. 1). In other words, the use of front groups is designed to shield the true identity of sponsors. In commercial terms, the most common use is on the part of corporations who work collectively through industry-based associations. We add the term stealth when these associations adopt names that serve to hide true interests of sponsors or, even worse, to misrepresent their positions. Front-group stealth campaigns appear to represent one agenda but, in fact, serve a very different agenda, often an agenda that is the opposite of what the group's name implies. Such campaigns are designed to influence via deception. In essence, they are "fraudulent campaigns" ("Ethics Month," 2004, p. 10).

The deceptive use of front groups is a violation of the PRSA Code of Ethics. The PRSA Code specifically identifies front groups as an example of improper conduct 
that violates provisions on full disclosure of information. PRSA members were cautioned during the 2004 Bush and Kerry presidential campaign that "assisting front groups that represent undisclosed sponsorships and/or deceptive or misleading descriptions of goals, causes, tactics, sponsors or participants constitutes improper conduct ... and should be avoided" ("PRSA's Stand," 2004, p. 14).

Americans have grown used to front-group stealth campaigns in politics, where interest groups adopt names that hide or misrepresent their true beliefs, raise funds, and launch campaigns for, but more often against, candidates or causes. This investigation, however, is interested in the use of front-group stealth in the commercial arena, although findings about their influence or the potential of antidotes may generalize to the political realm. Corporate use of front-group stealth campaigns has proliferated in recent years (Beder, 1998; Ellwanger, 2006; Rampton \& Stauber, 2001). Some corporations have discovered that, when they seek to influence attitudes about public policy, it is useful to disguise one's views "behind a name that suggests apparent objectivity," or even better, behind a name that suggests positive social values (Crossen, 1994, p. 146). They have deluded themselves into believing that the end justifies any means, including the use of names that communicate "corrupt information" (Crossen, 1994, p. 16).

The use of front-group stealth campaigns in the commercial realm is even more serious than their use in politics: for two reasons. First, corporate campaigns are often more deceptive than their political cousins because the names chosen for corporate front groups are much more likely selected with the intent to deceive, not just to hide sponsors' true intentions. Beder (1998) maintained that "the names of corporate front groups are carefully chosen to mask the real interests behind them" (p. 27). Second, whereas political initiatives are almost always contested — by the candidate who is attacked, by 527 groups who support the candidate under attack, and/or by journalists covering the campaign — corporate front-group stealth campaigns are seldom challenged; they tend to function under the radar screen and, as a result, their influence is more insidious.

Beder (1998) suggested the use of front groups and other advocacy groups allows corporations to take part in government behind community concerns, and "the names given to many of the [front groups] are confusing, if not downright deceptive" (Wilcox, Cameron, Ault, \& Agee, 2003, p. 72). For example, Exxon-Mobil funds front groups such as the Competitive Enterprise Institute and has for years funded U.S. advertising campaigns to convince the public that global warming is not a problem ("Behind the Lines," 2002). Likewise, Mokhiber (2000) alleged that Citizens for Better Medicare is a front group set up by the pharmaceutical industry to protect its multibillion-dollar profits.

\section{The Influence of Front-Group Stealth Campaigns}

We suspect that use of front-group stealth campaigns is so widespread because they work. Company communication specialists have discovered the lessons of 
corporate social responsibility: that people positively view organizations that appear to resonate with their own values (Cone, 2004). Indeed, many corporations-Dow Chemical, Mobil, DuPont, Amoco, Ford, Philip Morris, Pfizer, Monsanto, Proctor and Gamble, and others-are involved in multiple front groups (Beder, 1998). However, the impact of front-group stealth campaign initiatives has never been documented. The next section explores the reasons why such initiatives should work, offering a rationale based on theoretical explanations drawn from political science, philosophy, psychology, and public relations.

\section{Front-Group Stealth Campaigns Presume Low-Involved Receivers}

One explanation for why front-group stealth campaigns are effective is that the public is inherently low involved on matters of public policy and, hence, most people are unlikely to cognitively engage messages. As a result, deceptive titles and catchy slogans are able to exert considerable influence. A number of 20th century thinkers, including Lippmann (1922), Bernays (1923, 1928), and Dahl (1963) argued that the public is guided not by thought but by emotion and sentiment. They just don't care enough about public policy content to carefully scrutinize messages. Bernays (1928) believed that people "are largely uninterested" in public affairs (p. 117). Instead people are preoccupied with private affairs, making a living and being entertained, preoccupations that Arendt (1958) said distinguish mass societies. Lupia and McCubbins (1998) maintained that people are so involved with families, jobs, hobbies, and social commitments that they have little time left to inform themselves on political issues.

Dahl (1961) agreed that politics has low salience in the lives of most individuals. "Despite the great quantity of information about politics pressing in on all sides, the average citizen is remarkably deaf and blind to everything not of vital interest to him" (p. 264). Dahl believed that politics "lies for most people at the outer periphery of attention, interest, concern and activity" (p. 279). Instead, "at the focus of most men's lives are primary activities. ... [These] activities—not politics—are the primary concerns of most men and women" (p. 279).

Given limited interest in public affairs, people seek short cuts (Lupia, 1994). They function as "cognitive misers" (Stroh, 1995), oversimplifying complex content, seeking quick rather than accurate resolution, and rarely examining the basis of their beliefs or changing them (Fiske \& Taylor, 1991). Popkin (1991) described the shortcuts that people use to assess public affairs content as "low-information rationality." He maintained that the method is practical for people in a hurry. "It is a method of combining, in an economical way, learning and information from past experiences, daily life, the media and political campaigns" (p. 7). Dahl (1961) believed that even people who manifest interest in public affairs employ shortcuts to reduce effort. He explained that, "even for someone to whom politics is important, it is easier to be merely interested than to be active," that "interest is cheap, whereas activity is relatively expensive" (p. 280). 
In such a low-information environment, the content of messages is reduced to simple symbols and images. Bernays and others argued early on that effective persuasive messages must exploit simple symbols and images designed to connect with the values and interests of the audience. Lippmann (1922) believed that images and symbols could shape public opinion, and in the hands of persuasion-savvy elites, they could be used to achieve the "manufacture of consent." Ewen (1996) maintained that, "Lippmann saw the strategic employment of media images as the secret to modern power; the means by which leaders and special interests might cloak themselves in the 'fiction' that they stand as delegates of the common good" (p. 157).

Lippmann (1992) believed that simple symbols and images are able to trigger emotional responses in targeted receivers and at the same time undermine critical thought. However, he argued that symbols must be easily recognizable and resonate with accepted values of receivers. Popkin concurred. He (Popkin, 1991) argued that successful campaigns employ "symbols which are already clear and well-known" (p. 103). When corporate front-group stealth campaigns utilize catchy names, such as the "Coalition for Clean Air," they are making a statement about their alleged values that they think will resonate with those who support a clean environment, and they are counting on two things: one, that most receivers are not motivated to probe their messages much beyond the name, and second, that their deceit will go unchallenged by the elite media. On both counts, we suspect that they are correct.

The position that low-involved message processing is unique, eschewing thinking about arguments and evidence in favor of shortcuts, is captured in the dual processing models that came to dominate social psychology for three decades and have found their way into other disciplines. The elaboration likelihood model (ELM; Petty \& Cacioppo, 1986) and the heuristic systematic model (HSM; Chaiken, 1987) posit that high- and low-involved message processing are distinct. High-involved processing, termed central in the ELM and systematic in the HSM, is deliberate and thoughtful. The quality of the arguments and evidence offered are focal points. By contrast, low-involved message processing is more mindless. In the ELM, it results in peripheral processing, with emphasis on source considerations, the number of arguments presented, background music, pictorial images, and names (Gardiner, Mitchell, \& Russo, 1985; Petty, Cacioppo, \& Goldman, 1981; Petty, Cacioppo, \& Schumann, 1983), and in the HSM it results in heuristic processing, with emphasis on "a variety of extrinsic persuasion cues" (Chaiken, 1987, p. 32) that take the form of personal decision rules that "associate heuristic cues with a probability that the advocated position is valid" (Todorov, Chaiken, \& Henderson, 2002, p. 197). One example of such a rule is "I agree with groups that support my values."

Not only is low-involved message processing inherently superficial, consisting of few, if any, informational cues (Todorov et al., 2002), but it also interferes with the capacity to process message substance. Early research on the effects of distraction in persuasion revealed that external distraction disrupted argument processing, reducing people's ability to produce counterarguments (Keating \& Brock, 1974; Osterhouse 
\& Brock, 1970), and thereby reducing the importance of strong arguments in influence (Petty, Wells, \& Brock, 1976). Subsequent research indicated that, when people were distracted, peripheral cues, such as source credibility, played a more significant role in persuasion (Kiesler \& Mathog, 1968; Petty \& Cacioppo, 1986). If peripheral and/or heuristic processing inhibits counterarguing, the process people use to protect their attitudes from change, then it also should render people more susceptible to persuasion. Studies reveal that peripheral and/or heuristic processing, compared to central and/or systematic processing, renders attitudes less persistent and more resistant to attack (Chaiken, 1980; Chaiken \& Eagly, 1983; Mackie, 1987; Petty \& Cacioppo, 1986).

\section{Front-Group Stealth Campaigns Assume Truth Is Malleable}

Another explanation for the success of front-group efforts lies in the study of selfpresentation, particularly how people, as targets of influence attempts, respond to the self-presentation efforts of others (Schlenker, 2003). Self-presentation relies heavily on impression management, a technique for shaping an audience's impression of a person, group, object, or idea. Many times, impression management may involve outright deceit, which often goes undetected by observers, even in close relationships (DePaulo, 1994).

Because people utilize impression management and, therefore, deception in their daily lives (Schlenker, 2003), they are willing to give others, including message sources, some latitude and assume their self-presentations are authentic. This correspondence bias describes people's inclinations to attribute the behavior of others to internal states (Jones, 1990). Research indicates that the correspondence bias is even more pronounced when receivers are not engaged in active message processing (Gilbert, Krull, \& Pelham, 1988).

Goffman (1959) indicated that people are predisposed to believe that others are offering authentic selves and are communicating truthfully. He called this "truth bias" and argued that it is pervasive and persistent.

In the public arena, the notion of truth as malleable dates to the early 20th century and the writings of American philosopher William James. In Pragmatism, James (1907) argued that there are no absolute truths, but that truth is what is perceived and, therefore, relative. James (1995) proclaimed that "truth happens to an idea. It becomes true, is made true by events" (pp. 77-78). In other words, perception is reality.

James's writings influenced the two most prominent public relations councils of the era, Ivy Ledbetter Lee and Edward Bernays. Lee, a former journalist, accepted James's notion that "truth happens to an idea." Lee argued that facts represent nothing more than "an attempt to give you my interpretation of the facts," and that, if "suitable facts" could be gathered and disseminated, then "they become truth" (in Ewen, 1996, pp. 80-81). James and Lippmann influenced Bernays, who insisted that 
news was "subjective" and could be created (Ewen, 1996). Indeed, Bernays often created pseudo events by staging seemingly spontaneous events and was the first to use the term front group (Bernays, 1928).

If truth is indeed malleable, then it is easy to understand how front groups could select names strategically: names that resonate with targeted receivers' values, although they absolutely misrepresent the true intentions of sponsors. Such stealth efforts may be effective in shaping public perceptions; however, they also should prove to be unstable because they are grounded in deception. James recognized the instability of "truth" arrived at in this way. James claimed that perception is truth, at least if unchallenged. He compared truth to paper currency (in an era in which currency was backed by gold). He (James, 1907) explained that truth exists on a credit system and is passed along as long as no one challenges it, just like bank notes that are passed along until no one accepts them.

However, any benefits of front-group stealth campaigns would, necessarily, be limited to the specific attitude object, formed by equating the title of the front group with a desirable value, and would not transfer to unidentified corporate sponsors who, after all, remain invisible behind the scenes. Hence, it is not anticipated that front-group stealth campaigns affect people's perceptions of the image or credibility of corporate sponsors.

Furthermore, any impact on specific attitude objects should be ephemeral because research suggests that perceptions formed in low-involvement circumstances lack persistence and are more susceptible to change (Chaiken, 1980; Chaiken \& Eagly, 1983; Krosnick, 1988; Mackie, 1987; Petty \& Cacioppo, 1986). This would be especially true for perceptions formed as the result of impression management. Hence, it is predicted:

Hypothesis 1: Front-group stealth campaigns are effective in influencing people's perceptions about the targeted attitude object and in enhancing people's perceptions of the image, reputation, credibility, and citizenship of the front group itself; however, such campaigns fail to influence public perceptions of the corporate sponsors of front groups.

In addition, there is the potential that front-group stealth campaigns may backfire, if their true motives are made public. If such campaigns are challenged-if their initiatives are exposed as deceptive- then it is anticipated that front-group stealth campaigns would backfire, not only against efforts to shape the attitude object but also against perceptions of front groups and of their corporate sponsors. Thus, the current study posits that

Hypothesis 2: If front-group initiatives are exposed as deceptive, it results in a backlash, which undermines

1. public perceptions of the image, reputation, credibility, and citizenship of the front group; 
2. public perceptions of the image, reputation, credibility, and citizenship of corporate sponsors of the front group.

\section{An Antidote to the Influence of Front-Group Stealth Campaigns}

More than 40 years ago, McGuire (1964) shifted his focus from persuasion to approaches to induce resistance to persuasion. He (McGuire, 1970) reasoned, "The preoccupation of many social scientists with techniques for social influence has provoked increasing interest in techniques for developing resistance to persuasion" (p. 36). This phase of the investigation examines the potential of the inoculation strategy to confer resistance to the influence of corporate front-group stealth campaigns.

Borrowing from a medical analogy, McGuire (1961b) argued that administration of inoculation treatments work much like a vaccination: Individuals receive "weakened, defense stimulating forms of . . counterarguments" (p. 327) that strengthen attitudes so that they are resistant to potential counterattacks that people might come in contact with. Inoculation works through two mechanisms: Threat seeks to get receivers to acknowledge the potential vulnerability of an attitude to influence and functions as the motivational catalyst for resistance; refutational preemption raises and systematically refutes specific challenges to attitudes and provides the ammunition that can be used in counterarguing (McGuire, 1961b, 1964; Pfau, 1997). Early studies by McGuire (1961a, 1961b, 1962, 1964, 1966; McGuire \& Papageorgis, 1962; Papageorgis \& McGuire, 1961) and later studies by Pfau and colleagues (Pfau, 1997; Pfau et al., 2004; Pfau et al., 2003; Pfau, Szabo, et al., 2001), which operationalized threat and counterarguing, indicated that inoculation works, with the latter studies confirming that both of the theorized mechanisms play instrumental roles in resistance.

"There is no question that inoculation works" (Pfau et al., 2003, p. 39); supporting evidence is considerable. However, it is a myriad of applications of inoculation that make the theory so interesting. Inoculation has been applied to a number of applied contexts, in essence, protecting people's attitudes from persuasive campaign messages: in marketing (Compton \& Pfau, 2004; Pfau, 1992), public relations (Burgoon, Pfau, \& Birk, 1995; Wan \& Pfau, 2004), politics (An \& Pfau, 2004; Pfau \& Burgoon, 1988; Pfau, Kenski, Nitz, \& Sorenson, 1990), and other domains.

Inoculation treatments work largely by motivating receivers to bolster attitudes. It isn't dependent on the specific content contained in the refutational preemption phase of the inoculation treatment. That's what gives inoculation its power: A single inoculation treatment is capable of providing "a blanket of protection" that extends well beyond the specific content covered in the message (Pfau, 1997, p. 137). The best evidence for the potential of generic treatments is found in the research on refutational same and different treatments. Refutational same treatments raise and refute 
the same arguments featured in a subsequent attack; refutational different treatments feature generic arguments that are not contained in a later attack. Research findings consistently indicate that inoculation is equally effective whether refutational same and different treatments are used (McGuire, 1961a, 1962, 1964; McGuire \& Papageorgis, 1962; Papageorgis \& McGuire, 1961; Pfau, 1992, 1997; Pfau \& Burgoon, 1988; Pfau et al., 2004; Pfau et al., 1990; Pfau et al., 2003; Pfau, Szabo, et al., 2001; Pfau et al., 1997).

The ability of inoculation different treatments to protect against, quite literally, all possible counterarguments suggests that use of a generic inoculation message that targets the broad class of front-group stealth campaigns should be able to confer resistance to a specific front-group stealth campaign message that an individual may encounter. Furthermore, a study by Pfau, Park, Holbert, and Cho (2001) portends effectiveness. This Pfau et al. study used generic inoculation treatments against the corrosive influence of soft-money-sponsored political ads used to target candidates in the 2000 presidential campaign. The generic inoculation messages were effective in combating the damage of various specific soft-money ads to democratic values. Thus, this investigation predicts that, in comparison to individuals who receive no inoculation (controls), for those individuals who receive a generic inoculation pretreatment,

Hypothesis 3: Inoculation messages confer resistance to the influence of front-group stealth campaigns.

\section{Method}

The purpose of the current investigation was to assess the influence of corporate front-group stealth campaigns, in which companies join with others and adopt names designed to deceive. In addition, the investigation examined the effects of post hoc exposure of the deceptive practices of front-group stealth campaigns, and it explored the efficacy of an antidote to the influence of front-group stealth initiatives in the form of preemptive inoculation.

\section{Selection of Exemplars}

The first step was to select the companies and/or groups for inclusion in the current study. After examining a number of front groups who campaign on a variety of issues, investigators chose three active, established front-group exemplars, including frontgroup campaigns designed to: oppose government efforts to restrict wetlands' development or to regulate developers, oppose federal efforts to control prescription drug prices under Medicare, and oppose federal or state regulatory efforts to reduce litter.

The front groups used in the current study campaigned on these issues, selecting names for their groups that suggest support for values that, it was assumed, would 
resonate with most citizens (e.g., preserving U.S. wetlands, reducing drug prices under Medicare, and reducing litter) but in fact sought to undermine government action to achieve these ends. The three front groups selected for the current study, one for each of the causes, were: the National Wetlands Coalition (NWC), Citizens for Better Medicare (CBM), and Keep America Beautiful (KAB). Information about these front groups was secured from their Web sites, and information exposing them as front groups was retrieved online. A single, prominent corporate sponsor was selected for each of the front groups from among actual sponsors. Exxon-Mobil was chosen from among the corporate sponsors of NWC, Merck Pharmaceutical from the sponsors of CBM, and Pepsi-Cola from the sponsors of KAB.

\section{Participants}

Participants for the current study were recruited from introductory communication classes at three midwestern universities. A total of 204 research participants completed all four phases of the study (a retention rate of $92.2 \%$ of those who began the study at Phase 1).

\section{Experimental Materials}

Researchers prepared multiple messages for use in the investigation. Three frontgroup stealth campaign messages were prepared, one for each group. The messages were designed as press releases sponsored by the front group. Content was drawn from the front group's Web site. Front-group stealth campaign messages contained persuasive arguments designed to support the respective positions of the NWC, $\mathrm{CBM}$, and $\mathrm{KAB}$ on the issues in question: National Wetlands Coalition supports "balanced" and "reasonable" development of the nation's wetlands (and opposes federal efforts to restrict wetlands' development or regulate developers); Citizens for Better Medicare urges "improvements" to Medicare through the use of "private sector-based prescription drug benefits" (and opposes federal efforts to control prescription prices under Medicare); and Keep America Beautiful urges education and voluntary cleanup initiatives to reduce litter (and opposes federal or state regulatory efforts designed to reduce litter). Front-group stealth campaign messages ranged in length from 439 to 448 words.

Three messages designed to expose the front groups and the organizations that fund them were prepared, one for each cause. The messages were designed as news stories. Content was drawn from news stories exposing the front group and its sponsors, except that each message was adapted so as to identify only the single sponsor serving as the exemplar in the current study. These messages ranged from 443 to 448 words.

A single inoculation message was written to preempt the influence of front-group stealth campaign messages. The message contained generic content about the 
prevalence and the deceptive nature of front-group stealth campaigns. The inoculation message was designed to resemble a press release. It led with the header, "Beware of Groups that Seek to Mislead." A fictitious group called Citizens for Corporate Responsibility was used as the source of the inoculation message. The first paragraph of the inoculation message was designed to elicit threat. Threat was operationalized as warning of impending, potentially influential campaign initiatives on the part of front groups that are designed to change your values about the issue in question. The message employed statistics and anecdotal evidence to warn about the deceptive practices of front-group stealth campaigns. Length of the inoculation message was 648 words.

A dummy message was also created to administer to participants not receiving an inoculation message (controls). The dummy message was an editorial, "Foul Mouth and Manhood," written by Anna Quindlen, which appeared in Newsweek on July 12, 2004. It was edited down to 648 words, the same length as the inoculation message. The content of the dummy message was completely irrelevant to front-group stealth campaigns or the specific causes being addressed by those chosen campaigns. Rather, the dummy message addressed a wholly irrelevant question: the use of foul language in politics.

\section{Procedures}

The investigation was conducted in four phases. During Phase 1, the participants completed a questionnaire designed to provide basic sociodemographic information and to assess initial attitude and involvement levels on each of the three issues. After they completed Phase 1 questionnaires, participants returned them to an experimenter who examined the attitude results to determine whether participants had revealed a positive attitude on one or more of three issues (favoring government action: to restrict wetlands' development, control prescription prices under Medicare, or reduce litter). If participants manifested a positive attitude on only one issue, they were assigned randomly to either inoculation or control condition on that issue. If they displayed a positive attitude on two or more issues, participants were assigned randomly to either the inoculation or control condition on one of the favored issues in such a way so that the number of participants across the three issues remained relatively balanced. Although researchers sought a relatively equal distribution of participants across exemplars, they desired a roughly 6 to 4 ratio of inoculation to control participants. Researchers sought to achieve balance across all cells in terms of initial attitude: across exemplars and between inoculation and control conditions.

Researchers also attempted to ensure balance across cells on initial involvement levels. Issue involvement is the importance or salience of a particular attitude object to a receiver (Zaichkowsky, 1985). In the ELM and HSM, involvement is considered to be instrumental in determining people's motivation to process messages (Chaiken, 1980; Petty \& Cacioppo, 1986). Also, involvement functions as an important 
moderating variable in inoculation research (Pfau et al., 2004; Pfau et al., 2003; Pfau et al., 1997).

Preliminary results suggest that researchers were successful in achieving relative balance across groups on initial attitudes and involvement levels on the issues of favoring government action to restrict wetlands' development, control prescription prices under Medicare, and reduce litter. Balance was achieved: across exemplars (NWC, $n=69$ : initial attitude, $M=5.50$, involvement, $M=4.88$; CBM, $n=67$ : initial attitude, $M=5.65$, involvement, $M=5.06$; and KAB, $n=68$ : initial attitude, $M=$ 5.67, involvement, $M=5.02$ ); and between inoculation and control conditions (inoculation, $n=116$ : initial attitude, $M=5.62$, involvement, $M=5.06$; control, $n=88$ : initial attitude, $M=5.51$, involvement, $M=4.98$ ). None of these differences were statistically significant. Initial attitude and issue involvement featured 7-interval scales, which are described in detail in the Measures section. The pattern of means suggests moderate, but relatively positive, initial attitudes and moderate involvement levels. Moderate issue involvement is important because it constitutes a boundary condition for inoculation (Pfau et al., 1997).

After being assigned to a condition, participants completed questionnaire items appropriate to the condition they had been assigned to. Questionnaire items addressed the image, reputation, credibility, and citizenship of the respective front group (either NWC, CBM, or KAB) and the respective corporate sponsor (either Exxon-Mobil, Merck Pharmaceutical, or Pepsi-Cola). Phase 1 of the study was administered the first week in April over 5 days.

Phase 2 of the investigation was administered during the second week in April. During Phase 2, participants received either an inoculation message or dummy message (all participants assigned as controls received a dummy message). Participants then completed a questionnaire designed to measure elicited threat levels and counterarguing output (the number of arguments contrary to initial attitudes and the number of responses to those arguments). Phase 2 was administered over 5 days.

Phase 3 was administered during the third week in April. The Phase 3 booklets contained a single message followed by a questionnaire. Participants received a front-group stealth campaign message that featured persuasive arguments designed to support the respective positions of the NWC, CBM, or KAB on the issues in question. Following the message, participants completed a questionnaire designed to assess: attitude toward the issue (government action to restrict wetlands' development, control prescription prices under Medicare, or reduce litter), the image, reputation, credibility, and citizenship of the respective front group (either NWC, CBM, or $\mathrm{KAB}$ ), and the image, reputation, credibility, and citizenship of the respective corporate sponsor (Exxon-Mobil, Merck Pharmaceutical, or Pepsi-Cola). Phase 3 was completed over 5 days.

Phase 4 was administered during the fourth week of April. During Phase 4, participants read a message that exposed the front group and its respective corporate sponsor. After completing the message, participants completed a questionnaire that 
assessed attitude toward the issue, the image, reputation, credibility, and citizenship of the respective front group (either NWC, CBM, or KAB), and the image, reputation, credibility, and citizenship of the respective corporate sponsor (Exxon-Mobil, Merck Pharmaceutical, or Pepsi-Cola). Phase 3 took 5 days.

\section{Control and Manipulation Check Measures}

Issue involvement. Initial issue involvement was used to assign participants to conditions and served as a control variable in the inoculation analyses. Issue involvement was operationalized as the importance or salience of the issue. It was assessed at Phase 1 using an adaptation of the Personal Involvement Inventory (PII; Zaichkowsky, 1985). Six items of Zaichkowsky's PII were used in the current study including: means nothing/means a lot; unimportant/important, of no concern/of much concern; doesn't matter/matters to me; irrelevant/relevant; and insignificant/significant. Reliability of the issue involvement scale was .94 $(n=204)$.

Threat and counterarguing output. Threat and counterarguing output functioned as manipulation checks in the inoculation analyses. Threat and counterarguing output were assessed during Phase 2 for all participants. Elicited threat was measured using five bipolar adjective pairs used in inoculation studies conducted during the past 20 years. Participants responded to the prospect that they could come in contact with persuasive messages that might cause them to rethink their position on the issue in question. The scale items were: unintimidating/intimidating, safe/dangerous, not harmful/harmful, nonthreatening/threatening, and not risky/risky. Reliability of the threat measure was $.87(n=204)$.

Counterarguing output was assessed using open-ended responses in which participants identified possible arguments contrary to their own position and then listed potential responses to those arguments in the spaces provided. The procedure is based on the thought-listing technique that was pioneered by Brock (1967) and Greenwald (1968). However, past use of this technique alone has proven to be inadequate in inoculation research (Pfau et al., 1997). Eagly and Chaiken (1993) argued that thought listing does not reflect the amount of cognitive effort expended. In addition, thought listing, by itself, fails to acknowledge that respondents may view their own thoughts as varying in power and intensity, in cognitive and affective terms. Therefore, after generating their list of arguments contrary to their position and responses to those arguments, respondents rated perceived strength of arguments contrary to their position and strength of responses using a 1- to 7-point scale. No time limit was imposed on participants' efforts to identify arguments contrary to positions, list responses to those arguments, or rate the strength of arguments and responses. However, most participants completed the Phase 2 questionnaire, including these tasks, in fewer than 10 minutes.

One researcher counted number of arguments contrary to attitudes and responses to those arguments. The researcher counted all declarative statements that opposed a 
participant's position as an argument contrary to position and all statements that refuted, or answered, those arguments as a response. One unique response per space that met the criteria was counted, based on a scoring method previously employed by Brock (1967), Osterhouse and Brock (1970), and Petty et al. (1976). Redundant thoughts were excluded.

Because resistance is based on the premise that inoculation treatments trigger the internal process of generating responses to arguments opposing the individual's attitude, thus rendering attitudes less resistant to attack, and because the number of responses, by itself, does not reflect the perceived strength of responses, especially relative to strength of arguments contrary to attitudes, counterarguing output was operationalized in relative terms. Counterarguing output was computed, first, by multiplying the total number of arguments contrary to initial attitude by respondent perception of the average strength of those arguments and by multiplying the total number of responses to arguments contrary to initial attitude by respondent perception of the average strength of those responses. Second, the product of number and strength of arguments contrary to initial attitude was subtracted from the product of number and strength of responses.

\section{Dependent Measures}

Attitude toward the issue. Participants' attitudes toward the issue (government action to restrict wetlands' development, control prescription prices under Medicare, or reduce litter) were measured at Phases 1, 3, and 4. Attitude was assessed on all three issues at Phase 1 and, for those participants assigned to the front-group stealth phase of the study, on the particular issue they were assigned to, during Phases 3 and 4. Attitude toward the issue was measured with six bipolar adjective pairs developed by Burgoon, Cohen, Miller, and Montgomery (1978) and used in persuasion research for more than 25 years. Adjective pairs included: wrong/right, negative/positive, unfavorable/favorable, unacceptable/acceptable, foolish/ wise, and bad/good. The alpha reliabilities of the attitude toward issue measure were: at Phase 1, .92 $(n=204)$; at Phase 3, .96 $(n=203)$; and at Phase 4, .96 $(n=204)$.

Measures of perceptions of front groups and their corporate sponsors. People's perceptions of the image, reputation, credibility, and citizenship of front groups and their corporate sponsors were assessed during Phases 1, 3, and 4. The measures employed were developed by Dowling (2001). Dowling developed the measures as a result of his frustration with long-established measures employed by Fortune to identify America's Most Admired Companies. Dowling argued that Fortune's measures fail to distinguish a number of distinct dimensions such as corporate image and reputation. Dowling (2001) factor analyzed his measures and maintained that his measures clearly distinguish between the dimensions of image, reputation, credibility, 
and citizenship. Dowling's measures of people's perceptions of organizations have been adopted by a number of large marketing firms.

Dowling (2001) conceptualized corporate image as people's global perceptions of an organization. "Corporate image ... represents stakeholders' shared beliefs about what is distinctive, central and enduring about the organization" (p. 215). Image is based on organizational behavior and consists of cognition and emotion. Dowling's image measure consists of five 7-interval, Likert-type items that denote the name of the organization and the following characteristics: appears to be well managed, appears to be technologically driven, appears to be successful, appears to be innovative, appears to be customer focused (or for front groups, appears to be member focused), and appears to be competitive. Alpha reliabilities of the image measure were: for front groups: Phase 1, .79 $(n=204)$; Phase 3, .72 $(n=203)$; and Phase 4, $.80(n=204)$; and for corporate sponsors of front groups: Phase 1, .68 $(n=204)$; Phase 3, .88 $(n=204)$; and Phase 4, .87 $(n=204)$.

Dowling (2001) viewed corporate reputation as "the attributed values evoked from the person's corporate image" (p. 19). Dowling maintained that reputation reflects the underlying values of an organization whereas image reflects organizational behavior. He argued that reputation comprises "value-based descriptions of the organization and are designed to reflect stakeholders' values" (p. 215). In this investigation, reputation was measured using four Likert-type items that feature the name of the organization and the following attributes: appears to be an industry leader, appears to be honest, appears to be a good corporate citizen, and appears to be respected. Alpha reliabilities of the reputation measure were: for front groups: Phase 1, .77 $(n=204)$; Phase 3, .80 $(n=203)$; and Phase 4, .85 $(n=204)$; and for the corporate sponsors of front groups: Phase 1, $77(n=204)$; Phase 3, $.84(n=204)$; and Phase 4, .83 $(n=204)$.

Dowling (2001) considered organizational credibility as an output variable. Image and reputation may affect perceptions of an organization's credibility. Credibility was measured using four Likert-type scales that list the name of the organization and the following features: appears to have confidence, appears to be trustworthy, appears to show support, and appears to have a positive word of mouth. Alpha reliabilities of the credibility measure were: for front groups: Phase 1, .84 $(n=$ 204); Phase 3, .89 $(n=204)$; and Phase 4, $86(n=204)$; and for corporate sponsors of front groups: Phase 1, .84 $(n=204)$; Phase 3, .87 $(n=204)$; and Phase 4, .83 $(n=204)$.

Finally, Dowling (2001) conceptualized corporate citizenship in terms of people's global perceptions of the character of an organization. It is an output variable. Dowling's citizenship measure consists of five 7-interval, Likert-type scales that denote the name of the organization and the following attributes: appears to be well managed, appears to be technologically driven, appears to be successful, appears to be innovative, appears to be customer focused (or for front groups, appears to be member focused), and appears to be competitive. Alpha reliabilities of the citizenship measure 
were: for front groups: Phase 1, .84 $(n=204)$; Phase 3, .86 $(n=204)$; and Phase 4, $.90(n=204)$; and for corporate sponsors of front groups: Phase $1, .84(n=204)$; Phase 3, $.59(n=204)$; and Phase 4, .90 $(n=202)$.

\section{Results}

The current study examined the influence of corporate front-group stealth campaigns, in which corporations form associations that, in turn, adopt names that are designed to misrepresent their true intentions. Assuming that front-group stealth campaigns are effective, the study examined two potential remedies: the use of post hoc exposure of corporate sponsors and their intentions and the use of preemptive inoculation.

Hypothesis 1 predicted that front-group a stealth campaigns are effective in influencing targeted attitudes, eroding initial attitudes favoring federal efforts to restrict wetlands' development, federal legislation to control prescription prices under Medicare, or government regulatory efforts to reduce litter, and in enhancing perceptions of the image, reputation, credibility, and citizenship of the front group itself. However, Hypothesis 1 also posited that front-group stealth campaigns fail to influence public perceptions of corporate sponsors, who remain unknown. Hypothesis 2 predicted that, if front-group stealth campaigns are exposed, it produces a backlash against front groups and their corporate sponsors.

Hypotheses 1 and 2 were tested with a series of repeated measure ANOVA tests. Within-subjects effects were computed using the Greenhouse-Geisser adjustment, which corrects for problems with sphericity, and then by planned comparisons using Dunn's multiple comparison procedure (Kirk, 1982) for all predicted effects and correlated $t$-tests for any unpredicted effects. ${ }^{1}$

The omnibus results are reported first. Then, the patterns of means are examined more closely as Hypothesis 2 and 3 are each evaluated in turn. The repeated measures ANOVAs, with Greenhouse-Geisser corrections, revealed significant differences across Phases 1, 3, and 4 on attitude toward the issue in question, $F(2,383)=$ $5.10, p<.01, \eta^{2}=.025$; and on perceptions of front group image, $F(2,385)=9.07$, $p<.01, \eta^{2}=.04$; reputation, $F(2,331)=66.925, p<.01, \eta^{2}=.25$; credibility, $F(2$, $376)=59.73, p<.01, \eta^{2}=.23$; and citizenship, $F(2,342)=87.81, p<.01, \eta^{2}=.30$.

Hypothesis 1 predicted that front-group stealth campaigns are effective in the short term in influencing public perceptions about targeted attitudes and in enhancing perceptions of the image, reputation, credibility, and citizenship of the front group itself.

The results indicated that front-group stealth campaigns are effective in eroding public attitudes favoring federal efforts to restrict wetlands development, federal legislation to control prescription prices under Medicare, or government regulatory efforts to reduce litter. A planned comparison revealed that people's attitudes toward 


\section{Table 1}

Participants' Perceptions of Front Groups Across Time

\begin{tabular}{|c|c|c|c|}
\hline & Phase 1 & Phase 3 & Phase 4 \\
\hline Dependent Variable & $M(S D)$ & $M(S D)$ & $M(S D)$ \\
\hline Image $(n=203)$ & $4.26(.72)$ & $4.52^{\mathrm{a}}(.78)$ & $4.31^{\mathrm{c}}(.54)$ \\
\hline Reputation $(n=203)$ & $4.57(.82)$ & $4.87^{\mathrm{a}}(.94)$ & $3.94^{\mathrm{b}}(1.25)$ \\
\hline Credibility $(n=204)$ & $4.78(.91)$ & $5.15^{\mathrm{a}}(1.06)$ & $4.18^{\mathrm{b}}(1.20)$ \\
\hline Citizenship $(n=204)$ & $4.76(.81)$ & $5.12^{\mathrm{a}}(.97)$ & $3.99^{\mathrm{b}}(1.27)$ \\
\hline
\end{tabular}

Note: Perceptions of front-group image, reputation, credibility, and citizenship were measured using 1-7interval scales. Higher scores indicated more positive perceptions about front groups.

a. Significantly more positive perceptions following the administration of the front-group campaign message at Phase 3 compared to initial assessment at Phase 1 at $p<.01$.

b. Significantly more negative perceptions following exposure of the front-group's true intentions and corporate sponsors at Phase 4 compared to assessment at Phase 1 at $p<.01$.

c. Significantly more negative perceptions following exposure of the front-group's true intentions and corporate sponsors at Phase 4 compared to assessment at Phase 3 at $p<.01$.

the issues in question deteriorated between Phase $1(M=5.57)$ and Phase $3(M=$ 5.31 ), following exposure to the front-group stealth campaign message, $F(1,201)=$ 9.49, $p<.01, \eta^{2}=.02$.

The results also indicated that front-group stealth campaigns are effective in enhancing public perceptions of the front group itself. Planned comparisons revealed that people's perceptions of front groups grew more positive between Phase 1 and Phase 3, following exposure to the front-group stealth campaign message. This pattern manifested itself across all front group measures: image, $F(1,202)=15.95, p<$ $.01, \eta^{2}=.08$; reputation, $F(1,202)=10.875, p<.01, \eta^{2}=.06$; credibility, $F(1,203)=$ $15.69, p<.01, \eta^{2}=.08$; and citizenship, $F(1,203)=14.37, p<.01, \eta^{2}=.08$. The Phase 1 and 3 front group means are shown in Table 1. Finally, the results revealed no differences in people's perceptions of front-group corporate sponsors. The Phase 1 and 3 front-group corporate sponsor means are depicted in Table 2.

The pattern of results provides unequivocal support for Hypothesis 1. Frontgroup stealth campaigns undermined perceptions of the targeted attitude object, eroding support for federal restriction on wetlands development, federal legislation to control prescription prices under Medicare, or government regulatory efforts to reduce litter. In addition, the front-group stealth campaigns enhanced perceptions of the image, reputation, credibility, and citizenship of the front group itself. However, front-group stealth campaigns failed to influence public perceptions of corporate sponsors, who still were unknown to participants at Phase 3. The pattern of results was consistent across all measures.

Hypothesis 2 posited that, if front-group stealth campaigns are exposed, it results in a backlash against front groups and their corporate sponsors. The omnibus results 


\section{Table 2 \\ Participants' Perceptions of Front-Groups' Corporate Sponsors Across Time}

\begin{tabular}{|c|c|c|c|}
\hline & Phase 1 & Phase 3 & Phase 4 \\
\hline Dependent Variable & $M(S D)$ & $M(S D)$ & $M(S D)$ \\
\hline Image $(n=204)$ & $5.25(.90)$ & $5.36(.93)$ & $5.19^{\mathrm{b}}(.98)$ \\
\hline Reputation $(n=204)$ & $5.08(1.06)$ & $5.23(1.11)$ & $4.55^{\mathrm{a}}(1.29)$ \\
\hline Credibility $(n=204)$ & $5.15(1.01)$ & $5.26(1.16)$ & $4.63^{\mathrm{a}}(1.22)$ \\
\hline Citizenship $(n=202)$ & $5.01(.94)$ & $4.91(1.22)$ & $4.39^{\mathrm{a}}(1.26)$ \\
\hline
\end{tabular}

Note: Perceptions of front-groups' corporate sponsors' image, reputation, credibility, and citizenship were measured using 1-7 interval scales. Higher scores indicated more positive perceptions about front-groups' corporate sponsors.

a. Significantly more negative perceptions following exposure of the front-group's true intentions and corporate sponsors at Phase 4 compared to assessment at Phase 1 at $p<.01$.

b. Significantly more negative perceptions following exposure of the front-group's true intentions and corporate sponsors at Phase 4 compared to assessment at Phase 3 at $p<.05$.

for attitudes about the issue in question and perceptions of front groups across Phases 1,3 , and 4 were reported above. The omnibus results for corporate sponsors of front groups are reported next. The repeated measures ANOVAs, with Greenhouse-Geisser corrections, revealed significant differences across Phases 1, 3, and 4 on the dependent measures of perceptions of the corporate sponsors of front groups: image, $F(2$, $395)=3.39, p<.05, \eta^{2}=.02$; reputation, $F(2,363)=31.01, p<.01, \eta^{2}=.13$; credibility, $F(2,370)=22.73, p<.01, \eta^{2}=.10$; and citizenship, $F(2,380)=22.15, p<$ $.01, \eta^{2}=.10$.

Three sets of results are required to evaluate Hypothesis 2. Patterns of means are examined involving attitudes about the issue in question, perceptions of the front groups, and perceptions of corporate sponsors of front groups.

First, the results revealed that, when front-group stealth campaigns are exposed, the effects previously documented on targeted attitudes dissipate. A correlated $t$ test assessed Phase 3 attitudes toward the issue in question (supporting federal restriction on wetlands development, federal legislation to control prescription drug prices under Medicare, or government regulatory efforts to reduce litter) (previous results revealed that front-group stealth campaigns influenced Phase 3 attitudes), with Phase 4 attitudes, after exposure. The results, $t(202)=2.72, p<.01$, indicated that, following exposure, people's Phase 4 attitudes $(M=5.52)$ rebounded from Phase $3(M=$ $5.31)$ to near-Phase 1 levels $(M=5.57)$. In other words, exposure reversed the effects of front-group stealth campaigns on targeted attitudes.

Second, the results indicated that, following exposure, perceptions of front groups deteriorated, usually below Phase 1 levels. Planned comparisons on Phase 4 perceptions of front groups, following exposure, versus Phase 1 perceptions revealed that 
exposure significantly undermined perceptions. This was evident for perceptions of front group reputation, $F(1,202)=97.96, p<.01, \eta^{2}=.27$; credibility, $F(1,203)=$ 41.26, $p<.01, \eta^{2}=.21$; and citizenship, $F(1,203)=65.73, p<.01, \eta^{2}=.36$. Front group image didn't erode beneath Phase 1 levels; however, Phase 4 image declined significantly compared to Phase 3 image, following the front-group stealth campaign message, $t(202)=-3.05, p<.01$.

Third, the results revealed that exposure, which identified corporate sponsors of front-group stealth campaigns, damages perceptions of these corporations. The planned comparisons assessing Phase 4 perceptions of corporate sponsors of frontgroup stealth campaigns, following exposure, and Phase 1 perceptions found that exposure undermined corporate sponsors' reputation, $F(1,203)=63.67, p<.01, \eta^{2}=$ .21 ; credibility, $F(1,203)=42.43, p<.01, \eta^{2}=.21$; and citizenship, $F(1,201)=$ $48.525, p<.01, \eta^{2}=.28$. Perceptions of the image of corporate sponsors didn't drop beneath Phase 1 levels; however, Phase 4 image dipped below Phase 3 image, which was assessed following the front-group stealth campaign message, $t(203)=-2.235$, $p<.05$.

This pattern of results supports Hypothesis 2. All data support the position that, if front-group stealth campaigns are exposed, it produces a backlash. The backlash erodes the influence of campaigns on targeted attitudes, diminishes perceptions of front groups, usually below Phase 1 levels, and seriously damages perceptions of corporate sponsors, again usually beneath Phase 1 levels. In short, the results indicate that exposure totally negates the influence of front-group campaigns and damages corporate sponsors of such campaigns.

Finally, Hypothesis 3 predicted that inoculation messages confer resistance to the influence of front-group stealth campaigns. To evaluate this prediction, a one-way MANCOVA was computed assessing the effect of experimental condition (control vs. inoculation treatment) on: Phase 2 elicited threat and counterarguing output, which together indicate whether the inoculation manipulation took, Phase 3 and 4 attitudes toward the targeted issue, and Phase 3 and 4 perceptions of front groups. Initial attitude and issue involvement served as covariates.

The omnibus MANCOVA was nearly significant for the covariate of initial attitude, $F(12,174)=1.62, p<.10, \eta^{2}=.10$, with univariate tests revealing significant effects on Phase 2 elicited threat, $F(1,185)=3.95, p<.05, \eta^{2}=.02$, and Phase 4 attitude toward the targeted issue, $F(1,185)=10.59, p<.01, \eta^{2}=.04$. Betas were positive, thus indicating that initial attitude toward the targeted issue was positively related to Phase 2 threat and Phase 4 attitude. The omnibus MANCOVA also revealed a significant effect for the covariate of initial issue involvement, $F(12,174)=$ $2.50, p<.01, \eta^{2}=.15$, with univariate tests revealing significant effects on the dependent variables of Phase $3, F(1,185)=12.81, p<.01, \eta^{2}=.06$, and Phase 4, $F(1,185)=15.37, p<.01, \eta^{2}=.06$, attitudes toward the targeted issue. Betas were positive, thus indicating that initial issue involvement was positively related to Phase 3 and Phase 4 attitudes. 
Table 3

Effectiveness of Inoculation Treatments in Eliciting Phase 2 Threat and Counterarguing Output and in Promoting Resistance to the Influence of Front-Group Campaign Messages as Manifested in Terms of Participants' Time 3 and Time 4 Attitudes Toward the Issue and/or Cause Under Pressure From the Front-Group Campaign

\begin{tabular}{|c|c|c|c|c|c|c|c|c|c|c|c|c|}
\hline \multirow[b]{3}{*}{ Experimental Condition } & \multicolumn{12}{|c|}{ Dependent Measures } \\
\hline & \multicolumn{3}{|c|}{ Threat } & \multicolumn{3}{|c|}{$\begin{array}{c}\text { Counterarguing } \\
\text { Output }\end{array}$} & \multicolumn{3}{|c|}{$\begin{array}{c}\text { Time } 3 \\
\text { Attitude }\end{array}$} & \multicolumn{3}{|c|}{$\begin{array}{c}\text { Time } 4 \\
\text { Attitude }\end{array}$} \\
\hline & $n$ & $M$ & $(S D)$ & $n$ & $M$ & $(S D)$ & $n$ & $M$ & $(S D)$ & $n$ & $M$ & $(S D)$ \\
\hline Control condition & 88 & 3.46 & $(1.22)$ & 85 & .49 & $(.82)$ & 87 & 5.13 & $(1.34)$ & 88 & 5.27 & $(1.28)$ \\
\hline Inoculation condition & 116 & $3.76^{\mathrm{b}}$ & $(1.25)$ & 109 & $1.57^{\mathrm{a}}$ & $(.41)$ & 116 & $5.45^{\mathrm{a}}$ & (1.17) & 116 & $5.70^{\mathrm{a}}$ & $(1.05)$ \\
\hline
\end{tabular}

Note: Experimental condition was operationalized as control and inoculation treatment. Phase 2 elicited threat was assessed using 7-interval scales. Higher scores indicate greater elicited threat. Counterarguing output was operationalized as an average of participant identification of the number of responses to arguments opposing initial attitudes (counterarguments) times the average rating of those arguments minus the number of arguments opposing initial attitudes times the average ratings of those arguments. Higher scores indicate more counterarguing output. Participants' Phase 3 and Phase 4 attitudes toward the issue and/or cause were assessed using 7-interval scales. Higher scores signify more positive attitudes about the issue and/or cause and less influence of the front-group message designed to undermine those attitudes and, therefore, greater resistance.

a. Significant compared to control condition at $p<.01$.

b. Significant compared to control condition at $p<.05$.

The omnibus MANCOVA was significant for experimental condition $F(12,174)=$ $1.83, p<.05, \eta^{2}=.11$. Subsequent planned comparisons examining inoculation and control conditions revealed that the inoculation manipulation elicited Phase 2 threat, $F(1,185)=3.02, p<.05, \eta^{2}=.02$, and counterarguing, $F(1,185)=5.82, p<.01, \eta^{2}=$ .03 , as inoculation theory posits. In addition, compared to controls, the inoculation treatments protected participants against the slippage of targeted attitudes at Phase 3 , following the front-group stealth campaign message, $F(1,185)=3.75, p<.01, \eta^{2}=$ .02 , and at Phase 4 , following exposure of front groups, $F(1,185)=8.48, p<.01, \eta^{2}=$ .03 . There were no significant univariate effects involving front-group perceptions. These means are shown in Table 3.

The results support Hypothesis 3. Inoculation protects against the influence of front-group stealth campaign on targeted attitudes, although effects were modest.

\section{Discussion}

The current study examined front-group stealth campaigns, in which corporations, working collectively through industry-based associations, use deceptive 
names that mask true interests of sponsors in an attempt to influence public opinion on social and/or political issues of interest to industry groups. The current study began with the resignation that front-group stealth campaigns are effective in influencing public opinion, unless they are exposed as intentionally misleading, in which case they boomerang against sponsors. Finally, the experiment examined the potential of inoculation to preempt the influence of corporate front-group stealth campaigns. The pattern of results of the experiment offered unequivocal support for these expectations.

Despite their long history and proliferation of use in recent years, (Beder, 1998; Stauber \& Rampton, 1995), there has been no research about the influence of corporate front-group stealth campaigns or about potential remedies. The current investigation offered two arguments as to why such campaigns should work. Front-group stealth campaigns should work because the public is low involved on most matters of public policy (Bernays, 1923, 1928; Dahl, 1963; Lippmann, 1922), and in those circumstances people rely on shortcuts to process messages, including descriptive titles that are designed to resonate with the receiver's values (Dahl, 1961; Fiske \& Taylor, 1991; Lupia, 1994; Popkin, 1991). This rationale is consistent with the dual processing models, such as the ELM and HSM, which posit that peripheral cues like names (ELM) or decision rules such as, "I agree with groups that support my values" (HSM), dominate in low involving circumstances. Furthermore, such campaigns operate on the premise that truth is malleable, a position that traces its origins to James (1907) and was accepted by the two most prominent public relations councils of the 20th century, Ivy Ledbetter Lee and Edward Bernays.

The results indicated that front-group stealth campaigns were effective, at least in the short term. Front-group stealth campaigns eroded public attitudes toward the issue in question (public attitudes favoring government efforts to restrict wetlands development, federal legislation to control prescription drug prices under Medicare, and government regulatory efforts to reduce litter) and boosted perceptions of the front group, but not the corporate sponsor, which was as yet unidentified. In short, front-group stealth campaigns do exactly what corporate sponsors intend. They work, in part because the public is low involved on most issues; as a result, they do not cognitively engage campaign messages, relying on processing shortcuts, like an advocacy group's name that appears to resonate with people's values. This rationale is consistent with Bernays (1928), Lippmann (1922), and Popkin (1991), who maintain that simple images, like catchy names and slogans, are persuasive, and consistent with contemporary dual-processing models, such as the ELM and HSM, which maintain that low-involved message processing is superficial, consisting of very little substantive thought (Chaiken, 1987; Petty et al., 1981; Petty et al., 1983; Todorov et al., 2002).

However, this investigation argued that front-group campaign influence tends to be ephemeral, if challenged. James maintained that perception is truth, if unchallenged; however, it erodes in the face of counterinformation. Research in the dual processing 
domain reveals that those perceptions formed in low involving circumstances lack persistence and are readily susceptible to change (Chaiken, 1980; Chaiken \& Eagly, 1983; Krosnick, 1988; Mackie, 1987; Petty \& Cacioppo, 1986). The results of the current study supported the transient nature of front-group stealth initiatives, once exposed. When front-group stealth campaigns were subsequently exposed, the initial effects on public attitudes toward the issue in question and enhanced perceptions of front groups dissipated. Attitudes toward the issue in question reverted to precampaign levels and people's perceptions of front-group reputation, credibility, and citizenship dipped beneath precampaign levels. Also, perceptions of corporate sponsors of front groups boomeranged. Perceptions of corporate sponsors' image slipped to precampaign levels and perceptions of sponsors' reputation, credibility, and citizenship plummeted beneath precampaign levels. The results indicate that exposure, which reveals the corporate sponsors and true motives of corporate front-group stealth campaigns, backfires, not only against efforts to shape the attitude object but also against the image, reputation, credibility, and citizenship assessments of front groups and their corporate sponsors. In short, there is significant risk associated with front-group stealth campaigns, which sponsors ignore at their peril.

Finally, the investigation tested the potential of inoculation to provide an antidote to the influence of front-group stealth campaigns. The results indicated that inoculation can ameliorate the influence of front-group stealth campaigns on pubic attitudes toward the issue in question, in the current study minimizing such campaign's attempts to undermine public support for federal efforts to restrict wetlands development, federal legislation to control prescription drug prices under Medicare, and government regulatory efforts to reduce litter. However, inoculation did not effect public perceptions of front groups.

These results provide further evidence of inoculation's efficacy, particularly the effectiveness of generic inoculation treatments that target a broad class of campaigns (Pfau, Park, et al., 2001). However, overall inoculation effects were relatively weak. Although the inoculation manipulation took, as evidenced by the higher elicited threat levels and greater counterarguing output for inoculated versus control participants, the variances accounted for were low on all dependent variables: threat, counterarguing output, and Phase 3 and Phase 4 attitude toward the issue.

Overall, the current investigation suggests two antidotes to the influence of frontgroup stealth campaigns. Inoculation is a preemptive strategy. It deflects the influence of such campaigns on public attitudes toward social and/or political issues, which is the primary purpose of such campaigns. Exposure is a post hoc strategy. It reverses the influence of front-group stealth campaigns and undermines perceptions of front groups and corporate sponsors.

These findings are important because, otherwise, corporate front-group stealth campaigns operate unchecked. The results of this investigation indicate that frontgroup stealth campaigns exert significant influence on public attitudes. Yet they operate under the radar screen. As a result, their influence is more insidious. Given their 
growing role in the public arena, it is crucial for the public to learn the sponsors and intent of messages designed to sway opinion. Things are not always what they seem.

\section{Limitations}

We acknowledge two caveats about the results of the current investigation. First, the current study employed college undergraduates as participants. College undergraduates are not representative of the general population, and their political attitudes tend to be "more unstable, changeable, weak, and inconsistent" compared to older age cohorts (Sears, 1986, p. 522). As a result, the pattern of results of the current study may overstate the influence of front-group campaign messages and the impact of messages exposing front groups, although there is no reason to believe that it would affect the efficacy of inoculation treatments. Second, the methodology employed in the current study induced more cognitive activity than would be likely in a more natural setting. By presenting participants with messages, the current study called attention to them. In natural settings in which people view television or read newspapers or magazines, communication messages are less likely to be singled out for processing and, if they are noticed, they are more likely to be processed passively, absent cognitive engagement.

\section{Note}

1. The current investigation was interested in the influence of front-group stealth campaign messages, the impact of exposure of front groups, and the potential of inoculation to deflect the influence of frontgroup campaigns. The current study featured three front-group exemplars to ensure generalizability of findings, although no predictions or questions addressed differences between exemplars. Nonetheless, researchers tested for differences across exemplars on Phase 3 and 4 attitudes toward the issue (government action to restrict wetlands development, control prescription prices under Medicare, and reduce litter) and on Phase 3 and 4 measures of perceptions of the image, reputation, credibility, and citizenship of front groups and their corporate sponsors using one-way MANOVA. Scheffe post hoc tests were computed to assess mean differences for all significant omnibus effects. The pattern of results was consistent. At Phases 3 and 4, the Pepsi-Cola KAB front group and Exxon-Mobil NWC front group were more positively perceived than the Merck CBM front group, and Pepsi-Cola and Exxon-Mobil were more positively perceived than Merck. Because people's perceptions of the three front-group exemplars were similar at Phase 1, we can only speculate that the Pepsi-Cola KAB and Exxon-Mobil NWC front-group messages were more influential than the Merck CBM front-group message. However, inspection of the pattern of means across Phases 1, 3, and 4 in people's perceptions of front groups and their corporate sponsors and the pattern of means of inoculation and control participants revealed results consistent with the main findings of the current study. Furthermore, the results of a 3 (front-group exemplars) $\times 2$ (inoculation versus controls) MANCOVA revealed no interaction effects.

\section{References}

An, C., \& Pfau, M. (2004). The efficacy of inoculation in televised political debates. Journal of Communication, 54, 421-436. 
Arendt, H. (1958). Between past and future: Eight exercises in political thought. New York: Viking.

Beder, S. (1998). Global spin: The corporate assault on environmentalism (2nd ed.). White River Junction, VT: Chelsea Green Publishing.

Behind the lines: Esso's claim to care about the environment. (2002, November). Ecologist, 11.

Bernays, E. L. (1923). Crystallizing public opinion. New York: Boni and Liveright.

Bernays, E. L. (1928). Propaganda. New York: H. Liveright.

Brock, T. C. (1967). Communication discrepancy and intent to persuade as determinants of counterargument production. Journal of Experimental Social Psychology, 3, 269-309.

Burgoon, M., Cohen, M., Miller, M. D., \& Montgomery, C. L. (1978). An empirical test of a model of resistance to persuasion. Human Communication Research, 5, 27-39.

Burgoon, M., Pfau, M., \& Birk, T. (1995). An inoculation theory explanation for the effects of corporate issue/advocacy advertising campaigns. Communication Research, 22, 485-505.

Chaiken, S. (1980). Heuristic versus systematic information processing and the use of source versus message cues in persuasion. Journal of Personality and Social Psychology, 39, 752-756.

Chaiken, S. (1987). The heuristic model of persuasion. In M. P. Zanna, J. M. Olson, \& C. P. Herman (Eds.), Social influence: The Ontario Symposium (Vol. 5, pp. 3-39). Hillsdale, NJ: Lawrence Erlbaum.

Chaiken, S., \& Eagly, A. H. (1983). Communication modality as a determinant of persuasion: The role of communicator salience. Journal of Personality and Social Psychology, 45, 241-256.

Compton, J., \& Pfau, M. (2004). Use of inoculation to foster resistance to credit card marketing targeting college students. Journal of Applied Communication Research, 32, 343-364.

Cone. (2004). Multi-year study finds $21 \%$ increase in Americans who say corporate support of social issues is important in building trust. Retrieved November 12, 2005, from www.coneinc.com

Crossen, C. (1994). Tainted truth: The manipulation of fact in America. New York: Simon \& Schuster.

Dahl, R. A. (1961). Who governs? Democracy and power in an American city. New Haven, CT: Yale University Press.

Dahl, R. A. (1963). Modern political analysis. Englewood Cliffs, NJ: Prentice Hall.

DePaulo, B. M. (1994). Spotting lies: Can humans learn to do better? Current Directions in Psychological Science, 3, 83-86.

Dowling, G. (2001). Creating corporate reputations: Identity, image, and performance. Oxford, UK: Oxford University Press.

Eagly, A. H., \& Chaiken, S. (1993). The psychology of attitudes. New York: Harcourt Brace Jovanovich.

Ellwanger, S. (2006, April 10). Tip sheet: Lies, smears \& dirty tricks: An ugly (but true) PR story. PR News, p. 1.

Ethics month 2004: Understanding ethical dilemmas (2004, September). Public Relations Tactics, 8-11.

Ewen, S. (1996). PR! A social history of spin. New York: HarperCollins.

Fiske, S. T., \& Taylor, S. E. (1991). Social cognition (2nd ed.). New York: McGraw-Hill.

Frankfurt, H. G. (2005). On bullshit. Princeton, NJ: Princeton University Press.

Gardiner, M. P., Mitchell, A. A., Russo, J. E. (1985). Low involvement strategies for processing advertisements. Journal of Advertising, 14, 44-56.

Gilbert, D. T., Krull, D. S., \& Pelham, B. W. (1988). Of thoughts unspoken: Social influence and the selfregulation of behavior. Journal of Personality and Social Psychology, 55, 685-694.

Goffman, E. (1959). The presentation of self in everyday life. Garden City, NY: Doubleday.

Greenwald, A. G. (1968). Cognitive learning, cognitive response to persuasion, and attitude change. In. A. G. Greenwald, T. C. Brock, \& T. M. Ostrom (Eds.), Psychological foundations of attitudes (pp. 147-170). San Diego, CA: Academic Press.

James, W. (1907). Pragmatism: The meaning of truth. New York: Longmans Green.

James, W. (1995). Pragmatism. New York: Dover Publications.

Jones, E. E. (1990). Interpersonal perception. New York: Freeman.

Keating, J. P., \& Brock, T. C. (1974). Acceptance of persuasion and the inhibition of counterargumentation under various distraction tasks. Journal of Experimental Social Psychology, 10, 301-309. 
Kiesler, S. B., \& Mathog, R. (1968). The distraction hypothesis in attitude change. Psychological Reports, 23, 1123-1133.

Kirk, R. E. (1982). Experimental design: Procedures for the behavioral sciences (2nd ed.). Belmont, CA: Brooks/Cole.

Krosnick, J. A. (1988). The role of attitude importance in social evaluation: A study of policy preferences, presidential candidate evaluations, and voting behavior. Journal of Personality and Social Psychology, $55,196-210$.

Lippmann, W. (1922). Public opinion. New York: Free Press.

Lupia, A. (1994). Shortcuts versus encyclopedias: Information and voting behavior in California insurance reform elections. American Political Science Review, 88, 63-76.

Lupia, A., \& McCubbins, M. D. (1998). The democratic dilemma: Can citizens learn what they need to know? New York: Cambridge University Press.

Mackie, D. M. (1987). Systematic and nonsystematic processing of majority and minority persuasive communications. Journal of Personality and Social Psychology, 53, 41-52.

McGuire, W. J. (1961a). The effectiveness of supportive and refutational defenses in immunizing and restoring beliefs against persuasion. Sociometry, 24, 184-197.

McGuire, W. J. (1961b). Resistance to persuasion conferred by active and passive prior refutation of same and alternative counterarguments. Journal of Abnormal and Social Psychology, 63, 326-332.

McGuire, W. J. (1962). Persistence of the resistance to persuasion induced by various types of prior belief defenses. Journal of Abnormal and Social Psychology, 64, 241-248.

McGuire, W. J. (1964). Inducing resistance to persuasion: Some contemporary approaches. In L. Berkowitz (Ed.), Advances in experimental social psychology (Vol. 1, pp. 191-229). New York: Academic Press.

McGuire, W. J. (1966). Persistence of the resistance to persuasion induced by various types of prior belief defenses. In C. W. Backman \& P. F. Secord (Eds.), Problems in social psychology (pp. 128-135). New York: McGraw-Hill.

McGuire, W. J. (1970, February). A vaccine for brainwash. Psychology Today, 36-39, 63-64.

McGuire, W. J., \& Papageorgis, D. (1962). Effectiveness of forewarning in developing resistance to persuasion. Public Opinion Quarterly, 26, 24-34.

Mokhiber, R. (2000, July/August). Fronting for PhRMA. Multinational Monitor, 21, 38.

Osterhouse, R. A., \& Brock, T. C. (1970). Distraction increases yielding to propaganda by inhibiting counterarguing. Journal of Personality and Social Psychology, 15, 344-358.

Papageorgis, D., \& McGuire, W. J. (1961). The generality of immunity to persuasion produced by preexposure to weakened counterarguments. Journal of Abnormal and Social Psychology, 62, 475-481.

Petty, R. E., \& Cacioppo, J. T. (1986). Communication and persuasion: Central and peripheral routes to attitude-change. New York: Springer-Verlag.

Petty, R. E., Cacioppo, J. T., \& Goldman, R. (1981). Personal involvement as a determinant of argumentbased persuasion. Journal of Personality and Social Psychology, 41, 847-855.

Petty, R. E., Cacioppo, J. T., \& Schumann, D. (1983). Central and peripheral routes to advertising effectiveness: The moderating role of involvement. Journal of Consumer Research, 10, 135-148.

Petty, R. E., Wells, G. L., \& Brock, T. C. (1976). Distraction can enhance or reduce yielding to propaganda: Thought disruption versus effort justification. Journal of Personality and Social Psychology, $34,874-884$.

Pfau, M. (1992). The potential of inoculation in promoting resistance to the effectiveness of comparative advertising messages. Communication Quarterly, 40, 26-44.

Pfau, M. (1997). Inoculation model of resistance to influence. In G. A. Barnett \& F. J. Boster (Eds.), Progress in communication sciences: Advances in persuasion (Vol. 13, pp. 133-171). Norwood, NJ: Ablex.

Pfau, M., \& Burgoon, M. (1988). Inoculation in political campaign communication. Human Communication Research, 15, 91-111. 
Pfau, M., Compton, J., Parker, K. A., Wittenberg, E. M., An, C., Ferguson, M., et al. (2004). The traditional explanation for resistance versus attitude accessibility: Do they trigger distinct or overlapping processes of resistance? Human Communication Research, 30, 329-360.

Pfau, M., Kenski, H. C., Nitz, M., \& Sorenson, J. (1990). Efficacy of inoculation messages in promoting resistance to political attack messages: Application to direct mail. Communication Monographs, 57, 1-12.

Pfau, M., Park, D., Holbert, R. L., \& Cho, J. (2001). The effects of party- and PAC-sponsored issue advertising and the potential of inoculation to combat its impact on the democratic process. American Behavioral Scientist, 44, 2379-2397.

Pfau, M., Roskos-Ewoldsen, D., Wood, M., Yin, S., Cho, J., Kerr-Hsin, L., et al. (2003). Attitude accessibility as an alternative explanation for how inoculation confers resistance. Communication Monographs, 70, 39-51.

Pfau, M., Szabo, E. A., Anderson, J., Morrill, J., Zubric, J., \& Wan, H. (2001). The role and impact of affect in the process of resistance to persuasion. Human Communication Research, 27, 216-252.

Pfau, M., Tusing, K. J., Koerner, A. F., Lee, W., Godbold, L. C., Penaloza, L. J., et al. (1997). Enriching the inoculation construct: The role of critical components in the process of resistance. Human Communication Research, 24, 187-215.

Popkin, S. L. (1991). The reasoning voter. Chicago: University of Chicago Press.

PRSA speaking out on abuses. (1995, March 20). PR News, p. 1.

PRSA's stand on front groups. (2004, October). Public Relations Tactics, 14.

Quindlen, A. (2004, July 12). Foul mouth and manhood. Newsweek, 76.

Rampton, S., \& Stauber, J. (2001). Trust us we're experts: How industry manipulates science and gambles with your future. New York: Tarcher/Putnam.

Reilly, M. (2003, April 21). Politics makes strange bedfellows: It's a strategy that works. PR News, p. 1.

Schlenker, B. R. (2003). Self-presentation. In M. K. Leary \& J. P. Tangney (Eds.), Handbook of self and identity (pp. 492-518). New York: Guilford.

Sears, D. (1986). College sophomores in the laboratory: Influences of a narrow data base on social psychology's view of human nature. Journal of Personality and Social Psychology, 51, 515-530.

Stauber, J., \& Rampton, S. (1995). Toxic sludge is good for you! Lies, damn lies, and the public relations industry. Monroe, ME: Common Courage Press.

Stroh, P. K. (1995). Voters are pragmatic cognitive misers: The accuracy-effort trade-off in the candidate evaluation process. In M. Lodge \& K. M. McGraw (Eds.), Political judgment: Structure and process (pp. 207-228). Ann Arbor: University of Michigan Press.

Third-party endorsements help drive successful campaigns. (2003, April 14). PR News, p. 1.

Todorov, A., Chaiken, S., \& Henderson, M. D. (2002). The heuristic-systematic model of social information processing. In J. P. Dillard \& M. Pfau (Eds.), The persuasion handbook: Developments in theory and practice (pp. 195-211). Thousand Oaks, CA: Sage.

Wan, H.-H., \& Pfau, M. (2004). The relative effectiveness of inoculation, bolstering, and combined approaches in crisis communication. Journal of Public Relations Research, 16, 301-328.

Wilcox, D. L., Cameron, G. T., Ault, P. H., \& Agee, W. K. (2003). Public relations: Strategies \& tactics (7th ed.). Boston: Addison-Wesley.

Zaichkowsky, J. L. (1985). Measuring the involvement construct. Journal of Consumer Research, 12, 341-352.

Michael Pfau (PhD, University of Arizona, 1987) is professor and chair of the Department of Communication at the University of Oklahoma. His research focuses on mass media influence and on resistance to influence.

Michel M. Haigh (PhD, University of Oklahoma, 2006) is assistant professor in the College of Communication at Pennsylvania State University. Her research interests involve mass media influence and strategic communication. 
Jeanetta Sims (MA, Abilene Christian University, 1995) is assistant professor in the Department of Communication at Oklahoma Christian University and a doctoral student in the Department of Communication at the University of Oklahoma. Her research focuses on social influence, strategic communication, and organizational diversity.

Shelley Wigley (MA, Oklahoma State University, 1999) is assistant professor in the College of Mass Communication at Texas Tech University and a doctoral student in the Department of Communication at the University of Oklahoma. Her research interests involve social influence and strategic communication. 